and probably the patient's sight as well; and if in parallel cases we could get at the mucous membrane of the larynx and pharynx, and apply the same solution to it, I think the result would be as satisfactory.

N.B. Only one of these five cases was under my care; the other particulars I obtained subsequently from the mother, a very intelligent woman.

\section{CASES OF NERVE-DISORDER, RECORDED WITH REFERENCE TO THE PROBABLE OPERATION OF MALARIA AS A CAUSE.}

By C. Handfield Jones, M.B., F.R.S., Physician to St. Mary's Hospital.

SERIES II (continued.)

CASE vir. C. M., aged 39, single, a butler, was admitted August 17th, having been ill five weeks. $\mathrm{He}$ has been paralysed to a considerable extent in both hands, so that he cannot dress himself, nor pick up anything. His feet are also weak, and flap down in walking. The hands and arms ache at night, so that he cannot sleep. The paralysis is getting worse. $\mathrm{He}$ has derived no benefit from blisters to the neck. He feels very weak all over. The head is hottish, but he has not much pain in it. The tongue is coated at the back; the bowels costive; the skin natural; the pulse large, soft. The urine (examined some days later) was of specific gravity 1014, of good full colour, not albuminous. There was great if not com plete loss of sensibility in the parts paralysed. He states that his illness came on gradually, apparently from excess in drinking, not in venery. He never lost his consciousness.

He was treated from the first with five grains of quinin three times a day, which was continued till September $3 \mathrm{rd}$, when he was much better in himself; the power of the right foot much improved, of the left but little; the hands still very weak. Citrate of iron and quinine were then prescribed, in doses of ten grains three times a clay, with fifteen minims of tincture of nux vomica.

September 10th. The hands are improved, but are very numb, and get very weak towards night.

September 17th. The feet and hands are stronger. $H$ is very much better in himself; he can lift and hold better than he could; but the more delicate movements he cannot yet manage. He says this is from numbness and stiffuess of the fingers.

October 19th. He has been at Kingston, and is very much better. He has had no medicine during the last ten days. He can dress himself, and do anything almost. He still has some " dead thick" numb sensation in the fingers, and some "loose" sensation about the left leg; "it does not come up in walking so well as the other."

November ind. He is still further improved.

REMARKS. Whatever may have been the exact seat of the palsy in this case, it seems clear that it must be ascribed to a simple failure of nervous power, and not to organic alteration. The excess he had indulged in, I suppose, acted as a predisposing cause, impairing the tone and rosisting power of the nerve-structures; and then this gave way completely under the influence of the constitutio anni, which seems constantly, at the present day, to depress nervous force. A correct diagnosis of these cases is most important, but not, I think, always easy. The existence of great general debility (apart from the paralysis), and the juvantia and ladentia, are the chief points to look to.

CASE virr. H., aged 45, a labourer, was admitted July 9th. Whilst at work, he was seized with violent pain across the loins, and with numbness running down the legs. The urine was retained, so that he could not pass it; and there was in. voluntary discharge of fæces. When first seen, he was lying on his back at full length, the toes pointing straight out; the skin cold; the legs paralysed and insensible, even when pinched with the nail. He was quite unable to stir. He had no pain nor disorder elsewhere. He was quite conscious. $\mathrm{He}$ was ordered to have an enema of turpentine with aloes; and to take immediately five grains of calomel, with ten of compound jalap powder. After the enema and powder had acted freely, the limbs still remained powerless; the pain continued, but was relieved by the use of a croton-oil liniment.

July 11th. He was ordered to have ten grains of disulphate of quina three times a day.

July 12th. Sensation had returned.
July 13th. He is able to sit up in bed.

July 20th. He attended himself at the Dispensary.

July 23rd. He was well. The quinine had been continued during all the time.

Reyarks. This case was under the care of my friend Mr. Moullin, whose skilful management of it deserves great praise. It seems to have been very similar to the preceding, the disorder in both being functional, and not referrible to active hy peræmia affecting the nervous centres. Early treatment (not to say correct) is in these cases of much consequence to the obtaining of an early recovery. My case, which had been ill five weeks before I saw him, recovered much more slowly than Mr. Moullin's. Dr. West has dwelt on the same point as regards infantile paralysis. In Dr. Graves's clinical lecture on Paraplegia, a case is related where severe paroxysms of gastralgia and vomiting concurred with this form of paralysis, and where a careful post mortcm examination detected no organic alteration whatever. In such cases, nothing remains but to assume that the vis nervosa was primarily disordered, or failed. Such derangements in persons predisposed may be induced by various causes which enfeeble the general power, as, for instance, an attack of fever. In this case it is, I think, the malarious, rather than the typhoid or typhus, which exhibits the sequel of paralysis. This is what might have been expected, as the malarious miasm exerts its prostrating influence peculiarly on the nervous system. It is rather remarkable how small an extent of the nervous system may be affected by the paralysis. A boy, aged 14, was recently under my care, who, after fever, had paralysis of the left little finger; the rest of the hand was only rather weak.

CASE IX. E. Ph., cook, aged 43, was admitted December 19th. She had been ill about four weeks. She was first attacked with inflammation of the legs, which got well, and she returned to her work; but six days ago she began to lose the use of the right hand, and two days afterwards that of the left. The paralysis of the left hand for two days was complete, that of the right was not so much. The arms were not affected. The hands were numb, but not in pain. She is much confined to the house, and has been two months in a kitchen without going out. She has felt very weak, and has been overworked lately. She never had ague. She was living, when taken ill, near Reading. There is a small lake a quarter of a mile from the house, and springs of water round it. The passages and cellars were damp. She has suffered much with headache and giddiness, but not at the time of the attack. The skin is warm, moist; pulse 72, soft; the bowels are open. A blister was apylied to the neck; and she was ordered to take three times a day five grains of citrate of iron and quinine, with ten minims of tincture of nux vomica; and to have half ordinary diet.

December 23rd. The skin is cold; circulation languid; pulse very weak. The left hand is improving slowly; the right recovered on the day of admission. 'The blister is very sore.

December 30th. The left hand is all right; the pulse a great deal better and stronger; the skin warm. She went out soon afterwards, quite well.

Remarks. The foregoing is a slight case of functional paralysis, but sufficiently well marked. The failure of nervous power in the motor nerves may have been due simply to fatigue, or, which I think more probable, the fatigue impaired their resisting power, and left them prone to succumb under even a slight degree of endemic influence. I incline to the latter opinion, because I am not aware that any amount of over-exertion alone is adequate to produce paralysis.

The following personal account given by M. Bailly, of his own experience during his stay at Rome, will form a suitable sequel to the foregoing cases. After some previous symptoms, such as morning headache, palpitation after a midday meal, sleeplessness, and momentary giddiness, he suffered as he goes on to relate. "In the morning I was comfortable enough, but towards 3 or 4 P.3r. a state of malaise began, and went on in creasing, without my being able to fix myself its especial seat. $I$ had neither pain in the head nor in the abdomen, nor any rigors. However, there came on, little by little, a weakness of legs, very difficult to conceive as occurring in an individugl who, having never been bedridden, and experiencing no local symptoms, could not himself determine in what manner such a weakness was possible, when he examined successively th state of all his functions. .... All my functions were performed very well. Every day I went to the hospital to collect observations, and to examine the bodies of those whose illness I had watched; each time I walked about three-quarters of a league to dine at Rome; and, when I had to return home, I despaired sometimes of being able to get to the end of the way; so great 
was the singular weakness which I felt in the knees, not in the same degree, or rather not at all, in the other parts of the body. When I ascended a staircase, for instance, I. made use of my hands, with which I grasped the banister, and nearly as strongly as at any other time, so as to draw all my body towards the fixed point, and so to relieve my legs, which, with out this aid, could scarcely have fulfilled their habitual office. I am not surprised that some authors have admitted the existence of a lassitudinary fever; for, on examining what was most apparent in my state, there was nothing to be seen which an nounced distinctly the lesion of any particular function.... If this lassitude was produced by the same cause which determines adynamia in grave fevers, as in typhus, why was it not as great in the upper limbs as in the lower; in a word, why was it the only apparent symptom? Further, I may observe that this phenomenon is very common in the course of intermittent fevers." M. Bailly goes on to say that he was freed from all his symptoms by one hundred grains of quinine, taken in five days, and a vegetable diet. (Traité des Fièvres intermittentes Simples et Pernicieuses, pp. 151, 152.)

I can fully understand the state which the above extract de cribes, as I experience occasionally something of the same kind myself ever since I had an attack of quasi-aguish character during the prevalence of cholera in 1854. This consists in a sensation of slight uneasiness referred to the heart, which is aggravated by walking at all far, so that I have often felt weary at my heart, and not in my legs. It affects me for some days at a time, and I am free from it again for a long interval. There is nothing discoverably morbid about the heart's action.

CASE X. MI.S., aged 41 , of active but nervous temperament, resident in London, has been subject latterly to bronchitis in winter. One day, haring had a degree of stomach derangement for some time, she experienced all the symptoms of a com mencing catarthal attack. She had much cough, and felt bruised and sore all over. Two doses of carbonate of ammonia with compound camphor tincture were taken. In the night she fell ill, with quick pulse. About 8.30 the next morning, she was attacked with distress referred to the heart, a sensation as if she were dying, breathlessness, and anxiety. I saw her about 10 A.x., when I found the pulse at the wrist almost utterly gone; the hands cold; the same distress continuing; the action of the heart, on auscultation of the cardiac region, very rapid the sounds normal and loud; the face pale; and the eyes sunken. Her voluntary muscular power was not materially impaired; she sat up well, and stretched her limbs vigorously. More than once she expressed a dread of going to sleep, lest she should never wake again. She seemed too restless and anxious to sleep or lie down. Stimulants were given freely, mustard poultices applied to the pracordia, and the electromagnetic current passed from the nape of the neck to the same part. Very little improvement was produced for some time; the pulse continued fluttering and most indistinct; but at last warmth began to return in the hands, and the pulse improved. She took three grains of quinine at 11 A.s. and 1.30 p.x. For a good while before and after the latter hour, the cerebral functions were much disordered; she kept repeating the same question or remark again and again, in spite of all snswers and assurances. It was evidently a form of delirium. About $1: 30$ P.x. she became much quieter, but complained of extreme wealiness. The pulse was 108 , of tolerable force; the tongue remained clean, but appeared to her to be dry, though it was fairly moist. She vomited once about the middle of the day, and coughed up a few times a little phlegm; but all catarrhal symptoms had disappeared.

10 P.M. She complains of extreme debility, and perspirations breaking out. The tongue is clean; the pulse large, weak, above 100. It 5 and 9 P.Mr, three grains of quinine were given, and twelve grains more in the course of the next day, and so the following half-day. She then had a grain and a half of calomel and a little rhubarb, which brought away a large solid dark evacuation, and liquid stools after. The action of the purge depressed her much; but she passed a better night than the preceding, when she had a third of a grain of morphia. No medicine was now given till the day but one after the calomel, when she began to take infusion of serpentaria, with tincture of cinchona, iodide of potassium, and bicarbonate of potash. This was prescribed with respect to the possible cxistence of a rheumatic element in the disorder ; but no decided benefit was produced. After two days, citrate of iron and quinine were given, in five-grain doses, three times a day.

$\mathrm{Up}$ to this time she remained very weak, with very little power of taking food, and experiencing nervous sensations about the chest, which made her fear a relapse. On the morning of the fourth day after she had begun the ferrocitrate of quinine, she felt a fluttering of the heart and great weakness, but after midday she rallied. She had improved previously. One of her daughters, about the same time, had an attack of bronchitis, in which quotidian morning paroxysms of chilliness and depression occurred, ceasing only after the administration of quinine. The ferro-citrate of quinine was administered in rather larger doses for a week or ten days longer, by which time she was convalescent, and able to go out.

A few days afterwards, a relapse occurred. She was attacked February 3rd, about 11 P.sr., by decided rigors; with violent beating of the heart in repeated accès, between which she felt better; with great depression and mental disturbance, manifested, as before, by constant loquacity and a tendency to repeat the same thing and question over and over again. The pulse at $2 \cdot 30$ A.M., when I saw her, was soft and quick; the skin fully warm; the tongue parched and dried up, and coated. She complained of breathlessness; threw the clothes off her chest her legs fell as if they did not belong to her; and her hands tingled. I gave her fifteen minims of liquor opii sedativus, and twenty minims of chloric ether; but, though the symptoms gra dually subsided, she did not get to sleep till 5 A.M. At $7 \cdot 30$ A.M. she began to take two grains of disulphate of quinine every three hours.

February 5th. She was better all yesterday until 11 P.r., when the same symptoms recurred, but less severely. She got some tolerable sleep, but experienced a recurrence in the morning of disturbance of the heart's action, with a feeling as if she were dying. This subsided after some time, and she remained till the afternoon weak and depressed. The appetite was lost. She had whizzing in the ears from the quinine.

February 7 th. She passed a tolerably good day yesterday; the appetite, however, remaining very bad, and nausea being felt at times. Last night she was very bad. About 9 p.m. she began to have "internal tremors" and exceeding restlessness, which passed into high fever, and was succeeded by profuse sweating when at last she got to sleep. She is very weak and prostrate this morning, with much nausea and utter aversion to food. There is no enlargement of the liver or spleen. Her complexion is yellowish. She has some epigastric tenderness. The tongue is coated, dryish; the bowels are open. The quinine was omitted. A sinapism was applied to the epigastrium. She was ordered to have lumps of ice to swallow.

February 9 th. On the night of the 7 th, she slept well with thirty minims of morphia solution; last night she slept well without. She has been taking, to-day and yesterday, two grains of disulphate of quina three times a day. She is very weak, but has scarce any of her former symptoms, except gastric sinking and nausea.

February 10th. There was very much perspiration last night, and slight shivering and much depression this morning. The tongue is clean; pulse quick, good. She was directed to take five grains of citrate of quinine and iron, with six minims of tincture of nux vomica, three times a day.

Four days later, she went into the country, having materially improved before her departure. The change was productive of great benefit, and she returned apparently quite recovered. The stamp of aguish disorder, however, was still upon her, marked by evening chills, followed by slight flushes. Abou ten days after her return, she had a mild bronchitic attack, from which she recovered, and regained her ordinary health.

REMarks. It is difficult to make the narrative of a case like the preceding complete without being tedious. The salient points are cardiac neuralgia, paroxysms of aguish character, profound debility without any organic cause. 'The commence. ment of the affection, with the symptoms of incipient catarrh or influenza, is worthy of rernark. It seems impossible to viow the phenomena in any other light than as the results of a depressing poison operating on the nervous system, principally on the sympathetic and cardiac nerves. Syncopal tertian is well known in South America (vide Dr. Hamilton's pamphlet, p. 26), in Italy (Torti), and in France ('Trousseau). Its occurrence among ourselves is not common, but yet the cognate form of cardiac neuralgia is, I suspect, more frequent than most of us have any idea of. The term is used by Dr. Stokes as applied to what he designates simple neuralgia of the heart but I do not find that he connects it expressly with malarious disorder. Romberg also uses the terms cardiac hyperæsthesia and cardiac spasm, intending by the former angina pectoris; but he does not mention malarious disease as a cause of either. 
He quotes, however, in a note, a passage from Laennec, which I subjoin as exactly expressing my own opinion. "The majority of physicians have nevertheless remained persuaded, in England, in Germany, and especially in Italy, that angina pectoris is always connected with some orgaric disease of the heart, that this symptom is very serious, and that most of the patients who are attacked by it die suddenly. These ideas are by no means correct. Angina pectoris, in a slight or moderate degree, is an extremely common affection, and exists very often in subjects who have no organic affection of the heart or of the great vessels. I have seen many persons who have experienced only some very sharp attacks, but of short duration, and who have been subsequently freed from them. I believe even that the influence of the medical constitution contributes to the development of this affection; for I have observed it frequently in the course of certain years, and I have scarcely met with it in others. On the other side it is true that angina pectoris very often coincides with organic affections of the heart; but there is nothing to prove that it depends on them even in these cases, since it may exist without them, and these affections are very various." The italies in the above passage are my own. I do not consider the cardiac disorder in Case $\mathrm{x}$ as quite identical with angina pectoris; but it was evidently very similar, and was attended, as well as in Case XI, with a sense of impending death. The term angina pectoris is one which I should be glad to see disused; it leads the mind too much to think of the cardiac affection as something strange and peculiar, and so confuses the practitioner's ideas in the treatment. Cardiac neuralgia I consider a much better term; it groups the phenomenon in question with a class of others which we continually recognise and treat. It is always a gain to take away the idea of a special entity from a disease, and to view it as a morbid process, which has its narallels elsewhere. Dr. Walshe, in his comprehensive work on Disease of the Lungs and Heart, has a note to the effect " that angina of malarious origin, and recurring periodically, has been observed." Of this kind, insofar as its origin, was the case above related.

CASE XI. C. R., aged about 35, of sanguine habit, but rather weak nerve power, had been exposed to cold and got ehilled. The same day he went out again after a hurried meal, and on returning took his ordinary siesta. He awoke with a very curious sensation of spasmodic choking all along the œsophagus; this was rather increased by taking spirit and water. $\mathrm{He}$ went to bed, and appeared relieved by the warmth somewhat, so that he slept for about an hour. He then awoke in the most excruciating pain; could only lie in one position, viz., on his back, slightly inclined to the right side, with the left leg drawn up. He could not breathe without great pain. "I dared not," he says, "close my eyes, from experiencing that most awful sensation as if my heart would cease pulsating the agony I went through that night baffles all description." For two hours he was involuntarily kicking, though well aware that he was doing so; he seemed to have no control over his limbs; and if he chanced to kick himself the feeling was a most curious one, "as if one leg did not belong to the same body." $\Lambda$ mustard and turpentine poultice to the chest afforded some relief. When I saw him early the next morning the pulse was excited; the tongue pretty clean; urine scanty and high-coloured; no morbid sounds in heart or lungs. He took calomel and opium, each two grains, immediately, and had his chest rubbed with a liniment of aconite and onium. After sleeping two or three hours he awoke, and began to take muriate of ammonia and bicarbonate of potash in camphor mixture four times a-day. The next day the urine deposited a lateritious sediment; he was much better, and in forty-eight hours from the commencement of the treatment he was convalescent, and has had no relapse. He has, however, both before and after this attack, suffered from rheumatism, mus. cular and periosteal.

REmarks. In this highly interesting case the disorder seems clearly to have been of rheumatoid character, though much more approximating to the neuralgic than the inflammatory form. Its exact location is not easy to determine; but I think it is probable the sheaths of the dorsal nerves were especially affected. The heart's action may have been disordered as well as that of the œsophagus, by sympathetic co-ordination, the nerves of the parietes and of the viscera being linked together in their various $\pi \alpha \theta \eta \mu a \tau \alpha$. This seems not an uncommon occurrence. The sensation of not daring to sleep is one that I have remarked in other cases of cardiac neuralgia. The involuntary kicking may have proceeded from an excited state of the cord, induced by the irritation of the dorsal nerves. A man at present in St. Mary's under Dr. Chambers, who has had tropical fever, suffers from attacks of opisthotonos, controlled by quinine.

CASE XIr. M., aged 54, robust male, was under the care of a medical friend for some days on account of inflammation of the left testis, probably of gonorrhœal origin. It had been treated by three applications of six leeches each, and by other appropriate means. Considerable improvement had taken place when my friend visited his patient on the morning of the last day of his life. About the middle of the day M. was suddenly attacked with severe pain in the region of the heart, and sent at once for my informant. He arrived in about ten minutes after the receipt of the message, but the man was dead. My friend had had him under his observation for some length of time previous to this attack, and had treated him for gonorrhœa on one occasion. No attack similar to the fatal one had ever occurred before, at least no mention had been made of any, nor had he suffered from any serious illness. His mind had been harassed somewhat lately by domestic vexation.

I was present at the post mortem examination, and noted the following. Rigor mortis was well marked. The body was muscular, and in good condition. The heart was flabby, but presented no disease of the valves, no hypertrophy, nor dilatation. There was slight atheroma of the coronary arteries. The brain was not examined; all the other organs healthy, On more particular examination of the heart, its walls were observed to be perhaps rather thinner than usual, and the tissue of a less decided red than in the healthy state. The microscope showed some degree of fatty degeneration of the sarcous tissue, but not by any means enough (in my judgment) to account for death.

REmarks. In this case we have a healthy man, somewhat weakened and depressed, seized suddenly by a severe breastpang, which arrests the action of his heart, and proves fatal. There is no whit of evidence to prove that malaria had anything to do with the occurrence, but neither is there any to show any other causation. I do not for a moment imagine that other causes may not give rise to neuralgia; but what inclines me to consider that in this case it was produced by some endemic influence, or the constitutio anni, is the circumstance which this series is intended to illustrate; viz., the notable prevalence at the present time of disorders of malarial character. I by no means affirm the existence among us of a marsh miasm, only of some influence producing various phenomena most resembling those of obscurely developed ague. This point seemed to accord with the experience of most of the speakers when I read a paper on the subject before the Royal Medical and Chirurgical Society. I regard, then, the foregoing case as one of neuralgia, such as, had it occurred in the forehead, or hip, or elsewhere, would have caused only pain; it struck the heart and the man dies.

\section{[To be continued.]}

\section{PARAPLEGIA FROM GRADUAL SPINAL EFFUSION (?).}

By Wilitam Walker, Esq., F.R.C.S.Eng.

Mr. E., aged 45, modeller, a stout, well formed man, had always enjoyed good health, with the exception of being occrsionally troubled with dyspepsia and lumbaro. A vear ago, he had a fall down some stone steps, and bruised his back and side. A week's rest, under medical treatment, relieved him; and he felt no further inconvenience.

On November 3rd, of the present year, he was taken unwell at a tavern, whilst enjoying himself in the society of a few friends and neighbours, and was obliged to be led home. The following day he had rigors, pains in his back and limbs, which he ascribed to getting wet in the feet two days previously.

November 9th. I saw him with my friend Mr. Cornelius, under whose care he then was. $\mathrm{He}$ complained of pains in the chest and back; but there was no pain on strong pressure over the spinal column. He was unable to move his legs. On examining the abdomen, I found the bladder much distended. The pulse was 80; the tongue clean; the intellect clear; the eyes somewhat suffused. He had slight pain on the top of the head. The bowels were open; the skin moist; there was no vomiting. The urine was drawn off, which afforded him much relief. He had been taking colchicum mixture, with calomel and opium night and morning.

November 1lth. He appeared much the same. The lower extremities were paralysed; he had a crampy feeling in his 